\title{
Хроматографический метод определения хлорорганических соединений в нефти
}

\author{
Подлеснова Е.В. ${ }^{1}$, Ботин А.А. ${ }^{1}$, Дмитриева А.А. ${ }^{1}$, \\ Вартапетян A.P. ${ }^{2}$, Леонтьева C.A. ${ }^{1}$

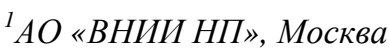 \\ ${ }^{2}$ ПАО «НК «Роснефть», Москва
}

Поступила в редакцию 8.04.2019 г.

DOI: $10.17308 /$ sorpchrom.2019.19/1173

На основании испытаний модельных и реальных образцов нефтей, содержащих ХОС в различных концентрациях, были определены показатели прецизионности разработанного метода. Также было проведено сравнение показателей точности разработанного метода с существующими стандартными методами определения ХОС. Как видно из полученных данных, разработанный метод имеет более низкий предел обнаружения и лучшие показатели прецизионности, чем существующие методы, что дает возможность определения более низких концентраций с высокой точностью.

Ключевые слова: хлорорганические соединения, газовая хроматография, электронозахватный детектор.

\section{Chromatographic method for determining organochlorine compounds in oil}

\author{
Podlesnova E.V. ${ }^{1}$, Botin A.A. ${ }^{1}$, Dmitrieva A.A. ${ }^{1}$, \\ Vartapetyan A.R. ${ }^{2}$, Leonteva S.A. ${ }^{1}$ \\ ${ }^{I}$ JSC «All-Russian Scientific Research Institute for Oil Refining», Moscow \\ ${ }^{2}$ Rosneft Oil Company, Moscow
}

Chlorine is present in the oil in the form of chloride salts, quite effectively removed at the stage of oil preparation, and in small quantities in the form of organochlorine compounds (HOS). HOS is practically not removed from oil at the stage of its preparation, which represents a serious danger to refining processes. Organic chlorine can form hydrochloric acid, which causes corrosion and destruction of equipment, and also leads to the formation of ammonium chloride in the form of deposits that disrupt the operation of heat exchange equipment.

In the 2000s. at a number of refineries in Russia, there were cases of emergency shutdowns of hydrotreating units for raw materials of the reforming unit, caused by volatile HOS added during the oil production stage. The use of HOS in the process of extraction, transportation and oil processing is unacceptable, as the traditional technology of oil treatment at ELOU does not ensure their removal, and the damage from their presence during oil refining is significant. Therefore, in Russian State standard 51858 "Oil. General technical conditions "standards were introduced on the content of organic chlorides in the fraction boiling up to $204^{\circ}$ C.

Standard methods for the determination of organochlorine compounds specified in Russian State standard 52247-2004 have a few significant drawbacks: the loss of light HOS during distillation, the inability to determine the qualitative composition of the compounds present, and hence the determination of their source. 
A perspective method for the determination of HOS in oil is the method of gas chromatography with an electron capture detector (ECD). In developing the method of determination, in order to obtain more reliable results, the test substances were divided into two groups, which should be determined with different modes of chromatography. The first group includes carbon tetrachloromethane, trichloromethane, dichloromethane, 1,2-dichloroethane, tetrachloroethene, trichloroethene, hexachloroethane, 1,1,1,2- tetrachloroethane. The second group includes chloronaphthalene, 1,1,2,2- tetrachloroethane. The detection limit of the method for HOS 1 group is $0.1 \mathrm{ppm}$, for HOS 2 groups - $0.3 \mathrm{ppm}$. When preparing calibration samples, reference isooctane was chosen as a solvent.

As a result of testing model and real samples of oils containing HOS in various concentrations, indicators of the precision of the developed method were determined. A comparison was also made of the accuracy indicators of the developed method with the existing standard methods for the determination of HOS. As can be seen from the obtained data, the developed method has a lower detection limit and better precision indicators than existing methods, which makes it possible to determine lower concentrations with high accuracy.

Keywords: organochlorine compounds, gas chromatography, electron capture detection.

\section{Введение}

Хлор присутствует в нефти в виде хлорсодержащих солей, а также в небольших количествах в виде хлорорганических соединений (ХОС). Природные примеси хлорсодержащих соединений представлены в основном хлористыми солями, которые достаточно эффективно удаляются до 3-5 мг/дм ${ }^{3}$ на стадии подготовки нефти [1]. Соединения хлора с углеводородами присутствуют нефти в значительно меньших количествах и представляют определенные трудности при удалении их из нефти, а их общее количество колеблется от 1 до 200 ppm.

ХОС практически не выводятся из нефти в процессах ее подготовки, что представляет серьезную опасность для процессов переработки. В реакторах риформинга и гидроочистки органический хлор может образовывать соляную кислоту, которая вызывает коррозию и разрушение оборудования, а также приводит к образованию отложений хлорида аммония, которые блокируют теплообменное оборудование блоков гидроочистки, а также стимулирует коррозионное растрескивание аустенитных сталей.

Особенно сильную коррозию хлористый водород вызывает в присутствии сероводорода. Авторы [1] показали, что скорость сероводородной коррозии в присутствии хлороводорода увеличивается в 100 раз. Кроме того, органический хлор является ядом для катализаторов риформинга и гидроочистки, что не только приводит к снижению мощности этих установок, но и может вывести их из строя.

В начале 2000-х годов на ряде НПЗ России были отмечены высокие скорости хлороводородной коррозии и отложения хлористого аммония на блоках предварительной гидроочистки сырья установок каталитического риформинга. Скорость коррозии достигала 2-4 мм в год, многократно превышая допустимые уровни. На некоторых заводах было зафиксировано до 10 аварийных остановок блоков риформинга, в связи с чем многие НПЗ понесли серьезные убытки. Позднее было выявлено [3], что причиной аварийных ситуаций являются летучие хлорорганические соединения в составе реагентов, которые добавляют в нефть на стадии добычи. Назначение таких реагентов различное, в том числе промывка скважин, растворение гидратов, асфальтенов, смол и т.д.

Применение ХOC в процессе добычи, транспортировки и переработки нефти недопустимо, так как традиционная технология подготовки нефти на ЭЛОУ не обеспечивает их удаление, а ущерб от их присутствия при переработке значителен.

До настоящего времени заводы не имеют технологий, позволяющих нейтрализовать хлорорганические соединения или же надежно защитить от них 
оборудование. Несмотря на существующие разработки в данном направлении [4], ни одну из них нельзя считать эффективной.

Таким образом, хлорорганические соединения являются дополнительным источником хлороводородной коррозии оборудования. Их наличие является потенциально опасным для НПЗ, а последствия их применения выявляются лишь в процессе ремонтных работ. Поэтому в ГОСТ Р 51858 «Нефть. Общие технические условия» были внесены нормы по содержанию органических хлоридов во фракции, выкипающей до $204^{\circ} \mathrm{C}$.

Методическое обеспечение определения содержания ХОС в нефти и распределения хлорорганических соединений по фракциям в процессе переработки сырой нефти является сложной задачей, так как:

- нефть представляет собой сложную смесь углеводородов с микросодержанием ХОС, измеряемым миллионными долями (ppm);

- нефть в значительных количествах содержит сераорганические соединения, которые мешают определению хлора.

Для снижения негативного влияния ХОС на процессы переработки нефти очень важно знать их количественное содержание.

\section{Эксперимент}

В настоящее время для определения ХОС используется стандартный метод [5], основанный на отгоне фракции нефти, выкипающей до $204^{\circ} \mathrm{C}$, и определении суммарного содержания следующими методами:

- Восстановление бифенилом натрия и потенциометрическое титрование;

- сжигание и микрокулонометрическое титрование;

- рентгенофлуоресцентное определение.

Данные методы имеют ряд существенных недостатков: потери легких ХОС при перегонке и невозможность определения качественного состава присутствующих соединений, а следовательно - установить их вероятный источник.

Перспективным методом определения ХОС в нефти является метод газовой хроматографии с электронозахватным детектором (ЭЗД).

Принцип действия ЭЗД основан на захвате молекулами анализируемых соединений свободных электронов, находящихся в ионизационной камере детектора. Отклик ЭЗД зависит от доли хлора в молекуле, поэтому требуется обязательная калибровка детектора. Чувствительность ЭЗД для четыреххлористого углерода составляет $2 \cdot 10^{-14}$ г/сек. Эти параметры могут меняться в зависимости от числа атомов хлора в молекуле.

Для того, чтобы сократить трудозатраты при проведении измерения содержания ХОС, а также исключить потерю легких ХОС при перегонке, определения хлорорганических соединений, необходимо производить напрямую в нефти. Для этого газовый хроматограф был оборудован системой обратной продувки, которая позволяет защитить хроматографическую колонку от загрязнения тяжелыми фракциями нефти.

В качестве определяемых веществ были выбраны хлорорганические соединения, которые наиболее часто применяются в составе реагентов и были обнаружены в более ранних исследованиях [6, 7]. При разработке метода определения, с целью получения более надежных результатов, исследуемые вещества были разделены на две группы, которые следует определять при разных режимах хроматографирования. К первой группе относятся: четыреххлористый углерод, хлороформ, дихлорметан, 1,2-дихлорэтан, перхлорэтилен, трихлорэтилен, 
гексахлорэтан, 1,1,1,2-тетрахлорэтан. Ко второй группе относятся 1-хлорнафталин, 1,1,2,2-тетрахлорэтан. Режим прибора для определения ХОС представлен в табл. 1.

Таблица 1. Режимы работы хроматографа с ЭЗД для определения ХОС группы

\begin{tabular}{|c|c|c|}
\hline \multirow{2}{*}{ Показатель } & \multicolumn{2}{|c|}{ Значение } \\
\hline & ХOC 1 группы & ХOC 2 группы \\
\hline \multicolumn{3}{|c|}{ Инжектор } \\
\hline Температура, ${ }^{\circ} \mathrm{C}$ & \multicolumn{2}{|c|}{280} \\
\hline Деление потока & $1: 5$ & Без деления \\
\hline Объем пробы, мкл & \multicolumn{2}{|c|}{1.0} \\
\hline \multicolumn{3}{|c|}{ Детектор ЭЗД } \\
\hline Температура, ${ }^{\circ} \mathrm{C}$ & \multicolumn{2}{|c|}{280} \\
\hline Скорость потока газа-азота & \multicolumn{2}{|c|}{30} \\
\hline \multicolumn{3}{|c|}{ Термостат колонки } \\
\hline Начальная температура колонки, ${ }^{\circ} \mathrm{C}$ & \multicolumn{2}{|c|}{80} \\
\hline Конечная температура, ${ }^{\circ} \mathrm{C}$ & 180 & 250 \\
\hline \multicolumn{3}{|c|}{ Колонка } \\
\hline Длина, м & \multicolumn{2}{|c|}{60} \\
\hline Внутренний диаметр, мм & \multicolumn{2}{|c|}{0.32} \\
\hline Толщина пленки, мкм & \multicolumn{2}{|c|}{0.5} \\
\hline Неподвижная фаза & \multicolumn{2}{|c|}{ полиэтиленгликоль в соль-гель матрице } \\
\hline Общее время анализа, мин & 20 & 30 \\
\hline
\end{tabular}

При выборе растворителя для приготовления градуировочных растворов было обнаружено, что большинство органических растворителей загрязнены хлорорганическими веществами на уровне миллионных долей. Наименее загрязненным растворителем оказался эталонный изооктан, поэтому он был использован в качестве основы для приготовления градуировочных растворов.

Реагенты, использованные для приготовления градуировочных растворов: четыреххлористый углерод (ЭКОС-1, >99.80\%); дихлорметан (Компонент-реактив, $>99.70 \%$ ); трихлорэтилен (Компонент-реактив, >99.90\%); хлороформ (Компонентреактив, >99.85\%); перхлорэтилен (Компонент-реактив, >99.70\%); 1,2-дихлорэтан (ЭКОС-1, >99.80\%); гексахлорэтан (Acros Organics, >99.00\%); 1,1,1,2-тетрахлорэтан (Honeywell, >99.00\%); 1,1,2,2-тетрахлорэтан (Biochem chemopharma, >98.50\%); 1-хлорнафталин (J\&K, >98.00\%).

Предел обнаружения метода для ХОС 1 группы составляет $0.1 \mathrm{ppm}$, для ХОС 2 группы - 0.3 ppm. На этом уровне концентраций для всех анализируемых компонентов соотношение сигнал/шум составляет не менее 40.

При работе с соединениями, содержащими в молекуле 4 и более атома хлора, наблюдалось ухудшение линейности зависимости массы вещества от площади пика на интервале концентраций, превышающем $10^{2}$. В этом случае необходимо строить отдельные градуировочные графики для более узких интервалов концентраций.

Примеры хроматограмм нефти одного из нефтеперерабатывающих заводов ПАО «НК «Роснефть» с внесенными в нее ХОС 1 и второй группы приведен на рисунках 1 и 2. На основании испытаний модельных и реальных образцов нефтей, содержащих ХOC в различных концентрациях, были определены показатели прецизионности разработанного метода, которые представлены в таблице 2. 


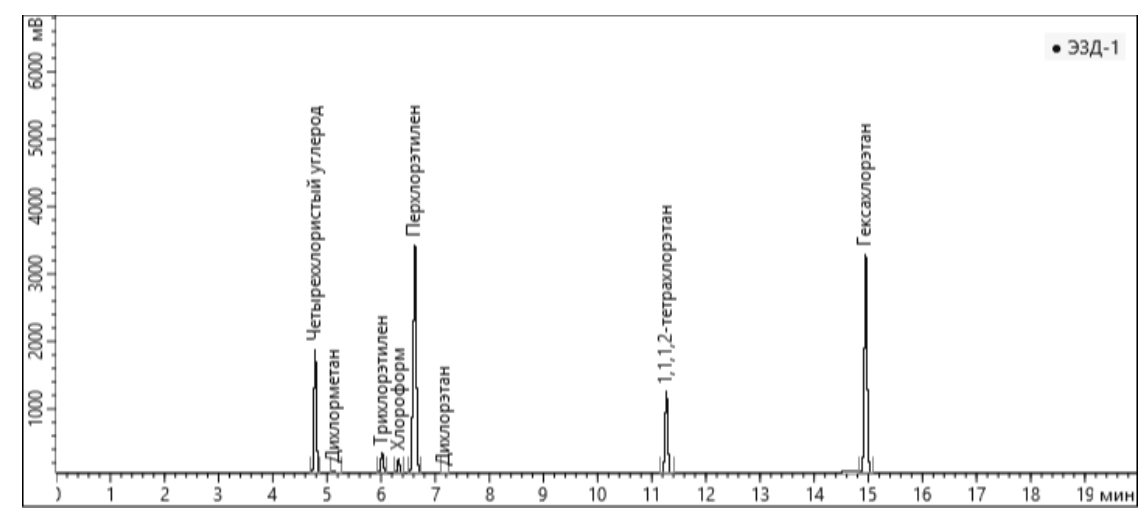

Рис. 1. Хроматограмма нефти, содержащей ХОС 1 группы

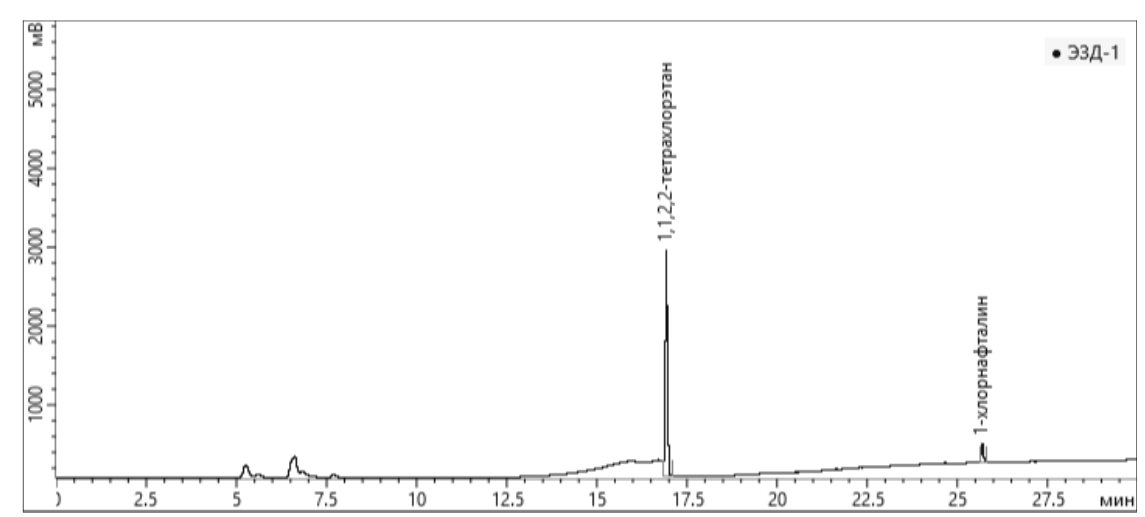

Рис. 2. Хроматограмма нефти, содержащей ХОС 2 группы

Таблица 2. Показатели прецизионности метода

\begin{tabular}{|c|c|c|c|c|c|c|}
\hline \multirow{3}{*}{$\begin{array}{c}\text { Наименование } \\
\text { хлорорганического } \\
\text { соединения } \\
\text { Измеряемая } \\
\text { концентрация, ppm }\end{array}$} & \multicolumn{6}{|c|}{ Показатели прецизионности, \% } \\
\hline & \multicolumn{3}{|c|}{ Повторяемость, $r$} & \multicolumn{3}{|c|}{$\begin{array}{c}\text { Внутрилабораторная } \\
\text { прецизионность, } R_{\text {л }}\end{array}$} \\
\hline & 0.10 & 1.00 & 5.00 & 0.10 & 1.00 & 5.00 \\
\hline $\begin{array}{c}\text { Четыреххлористый } \\
\text { углерод }\end{array}$ & 50.0 & 12.0 & 3.6 & 50.0 & 13.0 & 4.0 \\
\hline Хлороформ & 50.0 & 12.0 & 2.4 & 50.0 & 12.0 & 2.4 \\
\hline Дихлорметан & 50.0 & 12.0 & 2.4 & 50.0 & 12.0 & 2.4 \\
\hline 1,2-дихлорэтан & 20.0 & 10.0 & 6.0 & 30.0 & 13.0 & 6.0 \\
\hline Перхлорэтилен & 10.0 & 8.0 & 4.6 & 10.0 & 8.0 & 4.6 \\
\hline Трихлорэтилен & 30.0 & 10.0 & 3.8 & 30.0 & 10.0 & 3.8 \\
\hline Гексахлорэтан & 40.0 & 12.0 & 6.0 & 50.0 & 15.0 & 6.4 \\
\hline 1,1,1,2-тетрахлорэтан & 50.0 & 16.0 & 7.0 & 60.0 & 16.0 & 7.0 \\
\hline $\begin{array}{c}\text { Измеряемая } \\
\text { концентрация, ppm }\end{array}$ & 0.30 & 1.00 & 5.00 & 0.30 & 1.00 & 5.00 \\
\hline 1-хлорнафталин & 13.3 & 10.0 & 14.0 & 30.0 & 13.0 & 14.0 \\
\hline 1,1,2,2-тетрахлорэтан & 33.3 & 21.0 & 14.0 & 60.0 & 21.0 & 14.0 \\
\hline
\end{tabular}

Разработанный метод анализа ХОС в нефти реализуется на хроматографе «Кристалл-5000.2» фирмы ЗАО СКБ «Хроматэк».

\section{Обсуждение результатов}

Было проведено сравнение показателей точности разработанного метода с существующими стандартными методами определения ХОС [5]. Поскольку 
результатом анализа по разработанному методу является концентрация индивидуальных ХОС, a по стандартным методам - общее содержание органического хлора, для сравнительного анализа содержание общего хлора в образце по данным разработанного метода можно рассчитать по формуле:

$$
\omega=\sum_{i} \omega_{X O C i} \cdot \omega_{C l i}
$$

где $\omega_{\text {Хосі }}-$ содержание индивидуального ХОС в пробе, ppm; $\omega_{C l i}-$ массовая доля хлора в молекуле индивидуального ХОС, \% мас.

В таблице 3 приведено сравнение показателей точности существующих методов с разработанным, с учетом пересчета концентрации каждого ХОС на содержание хлора в молекуле. В таблице 4 представлена повторяемость рассматриваемых методов для концентраций 1 ppm и 5 ppm.

Таблица 3. Сравнение пределов обнаружения методов

\begin{tabular}{|c|c|c|c|c|}
\hline \multicolumn{5}{|c|}{ Предел обнаружения, ppm } \\
\hline Метод А & Метод Б & Метод В & $\begin{array}{c}\text { Разработанный ме- } \\
\text { тод, группа 1 }\end{array}$ & $\begin{array}{c}\text { Разработанный ме- } \\
\text { тод, группа 2 }\end{array}$ \\
\hline 1.00 & 1.00 & 5.00 & $0.07-0.10$ & $0.07-0.26$ \\
\hline
\end{tabular}

Таблица 4. Сравнение повторяемости методов

\begin{tabular}{|c|c|c|c|c|c|}
\hline \multirow{3}{*}{$\begin{array}{c}\text { Концентрация, } \\
\text { ppm }\end{array}$} & \multicolumn{5}{|c|}{ Повторяемость, \% } \\
\hline & \multicolumn{3}{|c|}{ ГОСТ Р 52247} & \multirow{2}{*}{$\begin{array}{l}\text { Разработанный } \\
\text { метод, группа } 1\end{array}$} & \multirow{2}{*}{$\begin{array}{l}\text { Разработанный } \\
\text { метод, группа } 2\end{array}$} \\
\hline & Метод А & Метод Б & Метод В & & \\
\hline 1.00 & 38.0 & 93.0 & - & $10.0-16.0$ & $10.0-21.0$ \\
\hline 5.00 & 18.6 & 42.2 & 26.0 & $3.8-7.0$ & 14.0 \\
\hline
\end{tabular}

Как видно из полученных данных, разработанный метод имеет более низкий предел обнаружения и лучшие показатели прецизионности, чем существующие методы, что дает возможность определения более низких концентраций с высокой точностью.

\section{Заключение}

Предлагаемый метод определения хлорорганических соединений в нефти имеет серьезные преимущества перед стандартными методами. При проведении исследования не требуется предварительная разгонка нефти, что упрощает анализ и исключает возможность потери легких ХОС. Идентификация индивидуальных ХОС позволяет выяснить, являются ли они природными или техногенными, что важно для внедрения способа снижения негативного влияния этих соединений на процессы переработки нефти. Стандартные методы определения хлорорганических соединений достаточно трудоемки и времязатратны, поэтому они уступают разработанному методу. Кроме того, разработанный метод имеет лучшие показатели прецизионности.

\section{Список литературы}

1. Левченко Д.М. и др. Эмульсии нефти с водой и способы их разрушения. М. Химия. 1987. $200 \mathrm{c}$.
2. Petty C., Kung R. Oil and Gas J. 1958. Vol. 2002.

3. Михайлова Е.О. Дисс. канд. хим. наук. M. 1986. 119 c.

4. Томин В.П. и др. Патент РФ. № 2221837. 56. No 33. pp. 350-352. 
5. ГОСТ Р 52247-2004. Нефть. Методы определения хлорорганических соединений. M. 2005. 15 c.

\section{References}

1. Levchenko D.M. et al. Emulsii nefti s vodoj i sposoby ikh razrusheniya. M., Khimiya, 1987, $200 \mathrm{p}$.

2. Petty C., Kung R. Oil and Gas J., 1958, Vol. 56, No 33, pp. 350-352.

3. Mikhajlova E.O. Diss. cand. chem. nauk. M., 1986, 119 p.

4. Tomin V.P. et al., Patent RF, № 2221837 , 2002.

Подлеснова Екатерина Витальевна - к.х.н., Всероссийский научно-исследовательский институт по переработке нефти, зав. лабораторией физических методов исследования, Москва, тел.: +79250754225

Ботин Андрей Арсеньевич - Всероссийский научно-исследовательский институт по переработке нефти, м.н.с. лаборатории физических методов исследования, Москва

\section{Дмитриева Анна Андреевна}

Всероссийский научно-исследовательский институт по переработке нефти, инженер лаборатории физических методов исследования, Москва

Вартапетян Александр Рубенович - к.х.н., Департамент промышленной безопасности, охраны труда и окружающей среды в нефтепереработке ПАО «НК «Роснефть», Москва

Леонтьева Светлана Александровна д.Х.н., Всероссийский научноисследовательский институт по переработке нефти, г.н.с. лаборатории физических методов исследования, Москва
6. Бабинцева М.В. Дисс. канд. хим. наук. Самара. 2008. 192 c.

7. Охлопков А.С. Дисс. канд. хим. наук. Нижний Новгород. 2015. 130 с.
5. Russian State standard 52247-2004. Oil. Methods for the determination of organochlorine compounds, M., 2005, 15 p.

6. Babintseva M.V. Diss. cand. chem. nauk. Samara, 2008, 192 p.

7. Okhlopkov A.S. Diss. cand. chem. nauk, Nizhny Novgorod, 2015, 130 p.

Podlesnova Ekaterina V. - Ph.D (chemistry), All-Russian Scientific Research Institute for Oil Refining, head of the Laboratory of Physical Methods of Research, Moscow, E-mail: podlesnovaev@vniinp.ru

Botin Andrei A. - All-Russian Scientific Research Institute for Oil Refining, junior researcher of the Laboratory of Physical Methods of Research, Moscow, E-mail: botinaa@ vniinp.ru

Dmitrieva Anna A. - All-Russian Scientific Research Institute for Oil Refining, engineer of the Laboratory of Physical Methods of Research, Moscow, E-mail: dmitrievaaa@vniinp.ru

Vartapetyan Alexander R. - Ph.D (chemistry), Department of Industrial Safety, Labor Protection and the Environment in the Refining of Rosneft Oil Company, Chief Specialist, Moscow, E-mail: a_vartapetyan@ rosneft.ru

Leonteva Svetlana A. - grand Ph.D (chemistry), All-Russian Scientific Research Institute for Oil Refining, Chief Researcher of the Laboratory of Physical Methods of Research, Moscow 